\title{
Em busca da complexidade esquecida
}

Edgar Morin gosta decitar uma passagem de Pascal: "Touteschosesétant causantes, aidées et aidantes, médiates et immédiates, et toutes s'entretenant par un lien naturel et insensiblequi lieles plus eloignées et lesplus différentes, je tiens impossible de connaître lespartiessans connaîtreletout, non plusque de connaître le tout sans connaître particulièrement les parties". ${ }^{1}$ Essa reflexão densa serve-lhe de base para a fundamentação da epistemologia da complexidade. Exposições e entrevistas mais longas levam-no quase semprea recorrer a essa chave deseu pensamento.

O fundamental para eleestá na reforma do fazer científico. Alain Touraine define-o como um intelectual interdisciplinar e incontornável: "Peut-être ne faut-il pas chercher unlieu central dansl'oeuvred'Edgar M orin, tellement sa richesse et sa séduction viennent desa capacitéderépondreà toutes les grandes interrogations du monde contemporain".2 Morin não conhecefronteiras e trabalha o conhecimento como aquilo que se "tece junto", de acordo com a origem latina da palavra "complexus". Na sua vasta trajetória dialógica marcada pela publicação de cerca de 30 livros, ele sempre se pautou pelabusca da contextualização, do sentido de uma totalidade hologramática, movediça, e da inter-relação das peças que formam o imenso puzzle das práticas sociais. Fora disso, o conhecimento parece-lhe despido de significação.

Pode, entretanto, um intelectual ser crítico sem anunciar o apocalipse? O francês Edgar Morin, nascido em 1921, prova que sim. N o tempo dejean-Paul Sartreintelectual engajado, os vendedores decertezas encantavam o mundo e afirmavam-se como gênios dareflexão devastadora. Passada a época das utopias racional istas, que prometiam o paraíso, mergulhadasnoirracionalismo metafísico e na arrogância de uma cientificidade insus- 
tentável, espal hou-sequenão haviamaisgrandesintelectuais para estudar a complexidade da vida. Magnífico erro. Edgar Morin nada deve aos mestres de 30 anos atrás.

Morin, porém, não vende ilusões. Homem desaber enciclopédico, tornou-seenfim umareferênciano pensamento europeu.Traz no coraçã̃o ena mentea convicção deque "le renoncement au meilleur des mondes n'est nullement le renoncement à un monde meilleur". ${ }^{3}$ Defato, a renúnciaao melhor dos mundosnãosignificaarenúnciaaum mundo melhor. Mudar não é preciso (em tempos de incerteza), mas éfundamental. Homem comprometido com a justiça social, não cessa de refletir sobre as noções de pátria, nação, universalismo, identidade, ecologia, política, comunidade, etc. Interessa-Ihe, dissecar os mecanismos para a compreensão da intrincada rede cultural contemporânea. N esse linha, os fenômenos da gl obalização e do recrudescimento dos nacionalismos xenófobos, elementos paradoxais para um mesmo período histórico, encontram finalmente explicação fora das teses redutoras. ${ }^{4}$

Inimigo feroz das simplificações, M orin combate os procedimentos científicos lineares, que recorrem a princípios finalistas mutiladores e à lógica binária cartesiana da separação arbitrária dos componentes deum conjunto fenomenológico. "Edgar Morin propose d'envisager la culture comme un systèmefaisant communiquer - dialectisant - une expérience existencielle, vécue, et un savoir constitué". ${ }^{5}$ Tudo écomunicação para Morin. A dialética, contudo, foi substituída pela dialógica, em nome da articulação do simples e do complexo, da ordem eda desordem, do separável edo não-separável. Elogio da racionalidade aberta.

A reformado pensamento capaz deevoluir da lógica clássica à dialógica complexa consistena superação das especial izações estanques que distanciam as várias áreas da pesquisa e impedem a conexão essencial entrecampos aparentementedestinados ao isolamento. Morin é um transgressor sempre pronto a chocar-se com as regras acadêmicas para tentar o salto na direção do novo. No abandono das certezas teóricas absolutas, operação de contestação do paradigma científico moderno, reside a sua maior luta epistemológica. Biodegradáveis, as certezas perecem a cada dia. As teorias nascem e morrem. Emfunção disso, perde-seoconsolo da redenção; ganha-se, em contrapartida, a lucidez do relativismo.

Em M es démons, obra na qual resume o seu percurso e as idéias obsessivas que o dominaram ao longo deuma vida deaventura intelectual, Edgar Morin conta como descobriu, duranteaSegundaGuerraM undial, o marxismo. $\mathrm{O}$ encantamento durou pouco. $\mathrm{O}$ ser da desconfiança já estava em ação. 0 marxismo não podia mais seduzi-lo por terse convertido, segundo a expressão tomada de empréstimo a Karl Korsch, numa "utopia reacionária". ${ }^{6}$ As asperezas do percurso underground incentivaram-no a investir na originalidadeabsoluta. Cornelius Castoriadis sintetiza: “L'unité et la singularité de la démarchedeM orin découlentd'uneintuition profondeet vraiedela spécificitédechacune des sphères de l'être en même temps que de leur solidarité indestructible". ${ }^{7}$

$\mathrm{O}$ eterno excluído, que se orgulha de não pertencer a nenhum grupo ou escola, escol heu o caminho da solidão: “ C'est quasi instinctivement que, devant toute idée je chercheson contraire. Jevissanscessel'assaut des vérités contraires, des impératifs contraires". ${ }^{8}$ Intel ectual, sugere, à quem através do ensaio, do texto derevista ou do artigo de jornal, com riqueza de informação, trata dos grandes questões humanas e explora até as últimas conseqüências a articulação confiança/ desconfiança. Os especialistas, costuma repetir com acidez, são, com freqüência, homens de saber al heios à dial ógica da complexidadeque não passam de gafanhotos simpáticos, quando isolados; predadores, em bando. Grande parte das dificuldades que enfrentrou, antes de ser reconhecido como um pensador de primeira grandeza, são explicadas por sua disposição em atacar os intelectuais: "Je ne respecte pas la loi du milieu". ${ }^{9}$ 


\section{Viver a imprecisão}

Em 1962, após um período de hospitalização em Nova York, Morin sentiu necessidade de escapar à podridão da comunidade intelectual, certo de que um indivíduo não deveafundar-senacaricaturadaprópriavida. Conhecedor de manobras acadêmicas, com as quais nunca concordou, sofreu as perseguições eo repúdio de uma corporação corroída, na época, pela mediocridade e soldada em nome do Progresso, do Saber, da Verdade, da Ciência e de outros termos de conhecida manipulação. $\mathrm{Na}$ contramão de todos os credos científicos, jogou a carta da incertezaemoposiçãoàsleishistóricasjamais demonstradas, recuperou o risco e o imprevisível como vetores naturais e recusou-sea aceitar o messianismo das esquerdas duras e desejosas de uma linearidade salvacionista.

Sempre a complexidade. Necessidade imposta pelo avanço do pensamento tecnocrático, pela ameaça dos fanatismos re ligiosos e pelo esquecimento da dimensão humana do Ser. Para Morin, adversário de todos os totalitarismos, respaldado por sua biografia de resistente ao nazismo, os meios decomunicação de massa eas universidades representam muitas vezes o papel de oponentes vigorosos da compreensão profunda dosdilemassociais. Não setratadeumataque gratuito ou ideológico à produção acadêmica. Ao contrário. Morin defende a reforma educacional quepermitaàuniversidadeocupar lugar decisivo na formação de homens voltados para a liberdade.

Pesquisador sem tabus temáticos, Edgar Morin debruçou-se sobre os problemas daculturadamassa. A imagem, por exemplo, é um de seus assuntos prediletos. Michel Maffesoli observa: “Receptáculo dos sonhos, o cinema constitui o elo mágico por excelência, pois sua estrutura, como analisa com peritinênciaE. Morin, permiteo jogo desombras, do sortilégio, da passividade, coisasque, como sabemos, são constitutivas da vida social".$^{10}$ Esse espaço do irredutível, do inútil, tem o seu preço. Os intelectuais e cientis- tas, embriagados pelo saber acrítico acumulado, adoram denunciar o cretinismo dos meios de comunicação de massa e dos incultos sem jamais admitir que os espíritos simples possuem também um saber ea capacidade de participar intensamente de emoções (a imersão num filme, por exemplo) e ainda assim estabelecer a diferença entre ficção e real idade. Os intel ectuais, afirma, são alienados, através de uma ideologia abstrata, típica do fetichismo moderno, que não podem suportar a alienação dos outros pelas tel enovelas ou pelo futebol. ${ }^{11}$

Irônico, Morin salienta o essencial: os intelectuais atacam o conformismo e os estereótipos e esquecem que eles mesmos formam uma subcultura convencional, cheia de estereótipos, conformista e preconceituosa. Além disso, arrogante. Nenhuma moda Ihe escapa: estruturalistas, marxistas, althusserianos, eliminadores da idéia de Homem e de Sujeito, crentes de toda a sorte, recebemasua parte. Solitário, M orin sabeque pouco pode contra os representantes da elitização de um saber impotente em relação à complexidade existencial, mas poderoso enquanto mecanismo de dominação.

Maffesoli sustenta que não existem enganados e enganadores, "mas uma atitude global". ${ }^{12}$ Morin persegue o ponto de intersecção entre as perspectivas opostas, o núcleo indefinível da ambigüidade, a encruzilhadadosinconciliáveis. Caminhadadeconfronto, segundo as suas próprias palavras, em duas frentes: contra a baixa cretinização gerada pela mídia e, na outra ponta, contra a alta cretinização alimentada pelos intelectuais. ${ }^{13} \mathrm{~A}$ guerra só poderia ser devastadora. De um lado, a abstração conceitual falsamente elucidativa (os ismos de todos os tipos). De outro, a recusa de teorias absurdas dando conta da morte do homem e do fim da noção de sujeito. Morin nãosedobroujamais: “J'ai étésouventsolitaire parcequejenepensepasselon lesalternatives et les évidences de la caste intellectuelle". ${ }^{14}$

Teórico em rota decolisão com as certezas imobilizadoras, M orin conserva-sesintonizado com o desejo de mudança social. A 
razão para o seu compromisso com a transformação é simples: o futuro povoa o imaginário doshomens ecobra projeçõesquerevelam, no mínimo, preocupações legítimas com o bem-estar dasgerações do amanhã. Sofre-se no presentea antecipação do devir. Deve-se, contudo, evitar de matar o aqui eo agora em função de uma religião do vir-a-ser. O futuro não pode ser convertido em doença do presente. A humanidade experimenta hojea de cadência deum tipo de idéia de futuro. Cabe construir uma nova concepção de devir passível de acolher uma confluência de sonhos.

Fugir à racionalização para alcançar a racionalidade, eisa aposta deM orin para que a humanidade continue a projetar o "mundo melhor" sem cair no reducionismo do "meIhor dos mundos". As misérias do Terceiro Mundo, é compreensível, fazem com que a tentação salvacionista reacenda a cada dia o mito, nem sempre confessado, da revolução nos corações inconformados com o capital ismo. OsleitoresdeM orin perceberãoquepara ele a construção do presente passa pela descoberta de um novo amanhã e pela ruptura com o projeto nostál gico de recuperação de um passado fracassado. Sociólogo deumaera de nebulosa, conforme Fages, M orin descobre que a profunda crise civilizacional exige uma "sociologie du présent". ${ }^{25}$

Se a cientificidade não é uma garantia delucidez política, aracionalidade-sistema aberto às contradições fundamentais do homem lúdico, produtivo e exposto constantemente à esquizofrenia societal - aparece como a mais elevada forma deconhecimento humano. Ao contrário da racionalização, fechada e calcificada logicamente, a racionalidade conjuga esforços argumentativos, de verificação, de crítica e de autocrítica e, mais do que tudo, rejeita argumentos de autoridade. O elogio da racionalidadefeito por Morin nunca deixade salientar os limites desse portentoso instrumento que possibilita o diálogo com o desconhecido, mas não apresenta respostas para tudo. ${ }^{16}$

Sociologia do presente, filosofia da incerteza, epistemologia da complexidade, teo- ria do acaso fundador, abertura ao impoderável, anseio radical de elucidação, paixão pelo diálogo, cruzamento de disciplinas: a obra de Edgar Morin é um convite à experimentação das dores e das delícias da "imprecisão", no sentido imortalizado pela poesia de Fernando Pessoa, cuja paráfrase moriniana por excelência poderia ser: compreender não épreciso. Fazer ciênciatambém não.

\section{A metodologia do Método}

A obra de Edgar Morin é uma ferramenta preciosa para a compreensão dos paradoxos da era da informação. Os quatro volumes de 0 M étodo ${ }^{17}$ situam com perfeição o intel ectual sempre em busca do caminho desconhecido einovador. Como tudo o que diz respeito à estrutura depensamento deM orin, 0 M étodo ultrapassa os limites da metodologia para configurar uma teoria e um imaginário epistemológico. Formidável libelo contra o positivismo e contra todo tipo de determinismo, essa apologia da compreensão vertiginosa supõe um infindável jogo de posiçõesederelativizações. A complexidade negocia com a incerteza, não para exorcizálas, o queéimpossível, masna perspectiva do estabelecimento de pontes provisórias entre o ser-que-busca e o desconhecido.

J. J. Le Moigne, exímio conhecedor da obra deEdgar Morin, toca o aspecto decisivo: “Unepenséequi sait qu'ellepeutrelier et que les liens qu'elle construit peuvent former ce prodige de l'esprit qu'est le entendement humain". ${ }^{18}$ Quando a atomização espreita, marca assustadora de sociedades performáticaseescravizadas pelaburocratização dossaberesedos poderes, a superação, ainda que sempre parcial, do esfacelamento intelectual pressupõe a valorização do conjunto, da totalidade multidimensional.

Estratégia da desintegração para a reconstrução, a compl exidade desmonta a totalidade totalizante, clássica e monolítica, com a preocupação teórica de estabelecer uma novatotalidadeaberta, circular, precáriaeem 
permanente intercâmbio com as suas partes. Morin está muito longe de ser um apologista da fragmentação categórica ou das virtudes da ausência da finalidade. Os finalismos deterministas, porém, não o convencem na medida em que ele questiona a própria finalidade da finalidade. Tudo o que concorre para a realização da vida não podedesviar-se da pergunta sobre a finalidade última do viver.

O grande perigo da obsessão finalista perversa está em que "cette rationalisation finalitaire devient symétrique à l'ancienne causalité élémentaire, car, comme elle, elle chassel'incertitude et la complexité". N ão se deveesperar dacomplexidade, enquantomeio de entender os fenômenos, uma arma para enfim eliminar a incerteza, descobrir os verdadeiros fins e estabelecer sem margem de erro a trama precisa dos objetos. A informação, vista como a finalidade suprema deste final demilênio, acaba por esconder ou negligenciar o sujeito da troca de signos. Informação para quê? Informação para quem? Os meios de comunicação tornaram-se sujeitos de si mesmos. A informação - fetiche desconsideraahumanidadedoshomens. Simplificar éa palavra-chave da mídia.

“Ainsi l'idée de finalité s'impose. Mais il fautnonseulementtempérer l'enthousiasme piagétien: il fautrelativiser etrelationnerl'idé edefinal ité". ${ }^{19}$ Morin não éo único a enfrentar as distorções dacientificidademoderna. $\mathrm{O}$ “Grupo dos 10", formado entre outros por Jacques Robin, Henri Atlan, Jacques Attali, Henri Laborit, Michel Serres, Joël de Rosnay e, claro, Morin, empreendeu nos anos 1960 uma cruzada contra o cartesianismo. Rosnay destaca a importância da "separação" cartesiana na edificação do esplendor científico atual, massocorre-sedeM orin para enfatizar que a inteligência parcelada, fruto dofracionamento dosproblemas, resultou no estilhaçamento da complexidade do mundo.

Implodir a fortaleza das verdades consumadas continua a ser o maior desafio dos adeptos de uma nova visão sistêmica: "Indispensable pour fonder la science, la démarche analytique ne suffit plus pour expliquer la dynamique et l'évolution des systèmes complexes, les rétroactions, les équilibres, l'accroissement de la diversité ou I'auto-organisation. II était donc nécessaire qu'émergent de nouvelles méthodologies d'organisation des connaissances face à la complexitédu monde". ${ }^{20}$ Caoseauto-organização entrelaçam-se. A ordem nasce da desordem. A desordem origina-se na ordem. Ordem edesordem geram o irreconhecível, o imprevisível. Nenhuma síntese acabada é possível.

Tomar, portanto, as ciências da complexidade como portadoras da salvação remete ao passadoetrai alógica dessesaportesplenos de inconformismo. A complexidade só permanece complexa na medida em que re conhece os seus limites e rejeita a burocratização. $0 \mathrm{M}$ étodo é um grito contra as tentações tecnocráticas do "metodologismo": "Lastérilitémenacetouttravail qui ne cesse pas de proclamer sa volonté de méthode". ${ }^{21}$ Edgar Morin conheceo valor do método, o que, de resto, não seria razoável contestar, nas difíceis veredas da pesquisa científica. No entanto, a exemplo de Paul Feyerabend, entende que "a ciência é um empreendimento essencial mente anárquico: o anarquismo teorético é mais humanitário e mais suscetível de estimular o progresso do que as suas alternativas representadas por ordem elei".22

O mundo confunde-se com os seus mitos. A ciência, altar da razão, mistura-se com as suas fantasias. Morin e Feyerabend foram longe nas denúncias contra a barbárie do conhecimento tecnocrático. A tarefa primordial do "cientista" não seal terou: transformar o conhecimento em sabedoria. Urge quebrar a arrogância dos metadiscursos, fomentar a interpenetração dos campos de investigação, relativizar o alcance de certas descobertas, estimular a curiosidade pura, acionar a máquina da desconfiança, multiplicar as perguntas, sonhar sempre com novas verdades, combater as vel has verdades injustas, etc.

Morin nomeia o "grande paradigma" e aponta osseusmales: avida, comsuaspaixões e sentimentos, reduzida ao cál culo, engolida 
pelo império da racionalização. Imaginários fabricados pela força do tempo e pela disseminação secular de modelos existenciais mutiladores. $\mathrm{Na}$ era da informação, a comunicação é um simulacro, um fantasma, uma ausência, uma recusa, uma quase impossibilidade: "La techno-science se forme, se ramifie, s'institutionnalise dans les universités, puisles entreprises industrielles, puis l'État. En deux siècles, elle passe de la périphérie au coeur de la sociéte". ${ }^{23}$ Onde podeainda manifestar-seo sujeito da contestação, o homem da alteridade, o ser da exclusão?

Mesmo que as brechas sejam mínimas, Morin não as despreza. Os intelectuais, os formadores de opinião, precisam retomar o trabal ho de discussão. Forjar idéias éfundar universos dialógicos. A dialógica não existe sem pluralismo, sem desvio, sem contestação, sem contra-informação, sem comunicação de sentimentos. A normalização, expressão máxima do conformismo, paralisa os intelectuais, arranca-Ihes a originalidade, tiraIhes a autonomia, impede-os de pensar por contra própria. Tudo éprevisto, das palavras permitidasàsteorias defensáveis: "A ussi peutonvoir, dansleshautessphèresintellectuelles universitaires, des exemples superbes de conformisme, qui n'y sont reconnusqu'après quelques générations". ${ }^{24}$

Intelectual, contudo, não são apenas o pesquisador, o professor, o cientista eo escritor; os jornalistas, no sentido amplo da palavra, também o são. Intel ectuais que há muito abdicaram do prazer e da obrigação derepudiar o conformismo. A mídia quer distância da complexidade. A simplificação émais rentável. A crítica da mídia não se volta jamais contra a própria mídia. As exceções servem delegitimação, simulacro deautocrítica. Produtoreseproduzidos por umimaginário que os engloba, os meios de comunicação, para serem examinados em profundidade, devem ser submetidos a complexas radiografias à luz do paradigma que os justifica.

Edgar Morin não deve ser entendido como o inimigo dos intelectuais. Amigo das idéias, conserva a força da rebeldia. A com- plexidadeimplica afrontar as verdades caseiras, as certezas confortáveis e, por vezes, até mesmo os ideais mais caros e aparentemente generosos. A irreverência epistemológica vai além doscompromissosideológicosesignifica a exegese de todas as ideologias. Exercício constante de dialógica - colocar em relação o exame dos pressupostos de um projeto, de umaidéia, deuma posição, etc.- deslegitima aspretensõesuniversalistasatemporaisefundamenta a evolução paradigmática. Edgar Morin simboliza o eterno retorno da dúvida.

\section{Notas}

1 MORIN, Edgar. La méthode - 1. la nature de la nature, Paris, Seuil, 1977, p. 7.

2 TOURAINE,Alain. "Edgar Morinetlechancesdelaliberté". In: Les jardins de la connaissance, Paris, Université Euro-arabe Itinérante, ํㅡ 2, outubro de 1995, p. 29.

3 MORIN, Edgar. "La pensée socialiste en ruine". In: Le Monde, Paris, 21/ 04/ 1993, p. 2. Nesse artigo extraordinário, Morin lembraquepara Marx: "Iascienceapportaitlacertitude", sendo o mundo determinista; de resto "ni l'imaginaire ni le mythe nefaisaient partie de la réalité humaine profonde". Em oposição aisso, Edgar Morin sustentaquenão sepode "opposer un futur radieux à un passé de servitudes et de superstitions. Toutes les cultures ont leurs vertus, leurs expériences, leurs sagesses, en mêmetempsqueleurscarencesetleursignorances".

4 Ver MORIN, Edgar. Terra-pátria, Porto Alegre, Sulina, 1995. Uma das epígrafes do livro, colhida na obra do escritor Ernesto Sabato, já diz muito sobre a maneira de pensar de Morin: "Precisamos de mundiólogos" (p. 5).

5 FAGES, J. B. Comprendre Edgar M orin, Paris, Privat, 1980, p. 159.

6 MORIN, Edgar. Mes démons, Paris, Stock, 1994, p. 246.

7 CASTORIADIS, Cornelius. "Morin le cheminant". In: Les jardins de la connaissance, op. cit., p. 39.

8 MORIN, Edgar. Mes démons, op. cit., p. 83. 
9 Idem, p. 96.

10 MAFFESOLI, Michel. A conquista do presente, Rio de Janeiro, Rocco, 1984, p. 65.

11 MORIN, Edgar. M es démons, op. cit., pp. 263-264.

12 MAFFESOLI, M. A conquista do presente, op. cit., p. 110.

13 MORIN, Edgar. M es démons, op. cit., p. 217.

14 Idem, p. 258.

15 FAGES, J. B., Comprendre Edgar M orin, op. cit., p. 123.

16 Sobre esse aspecto, ver. MACHADO DA SILVA, Juremir. "Entretien avec Edgar Morin, penseur dela complexité". In: Les jardins de la connaissance, op. cit., pp. 22-27.

17 Ver MORIN, Edgar. La méthode- la nature dela nature, Paris, Seuil, 1997, vol 1.

_. La méthode- La viedela vie, Paris, Seuil, 1980, vol II. L La méthode- la connaissance dela connaissance, Paris, Seuil, 1986, vol III.

. Laméthode- lesidées, leur habitat, leur vie, leurs moeurs, leur organisation, Paris, Seuil, 1991, vol IV.

18 LE MOIGNE, J.J., "Une pensééqui relie..." In: Les jardins de la connaissance, op. cit., p. 34.

19 Idem, p. 267.

20 ROSNAY, Joël de. L'hommesymbiotique- regard sur letroisième millénaire, Paris, Seuil, 1995, pp. 37-38.

21 BARTHES,Roland, apud JEANNENAY, Jean-Noël. Une histoiredes médias - des origines à nos jours, Paris, Seuil, 1996, p. 9.

22 FEYERABEND, Paul.Contraométodo, Riodejaneiro, Francisco Alves, 1977, p. 17.

23 MORIN, Edgar. La méthode- lesidées, leur habitat, leur vie, leurs moeurs, leur organisation, op. cit., p. 228.

24 Idem, p. 26. 